\title{
Tarefas da educação lingüística no Brasil ${ }^{1}$
}

Marcos Bagno

$\mathrm{UnB}$

Egon de Oliveira Rangel

PUC-SP

Com base no conceito de "educação lingüística", os autores discutem a necessidade de atender às demandas sociais por essa educação lingüística e definem as áreas de reflexão e atuação mais importantes para a implementação de uma política de educação lingüística no Brasil.

Based on the concept of "linguistic education", the authors debate the need of responding to the social demands for this linguistic education and define the most important areas of reflection and action for the implementation of a politics of linguistic education in Brazil.

\section{Introdução}

Entendemos por educação lingüistica o conjunto de fatores socioculturais que, durante toda a existência de um indivíduo, lhe possibilitam adquirir, desenvolver e ampliar o conhecimento de/sobre sua língua materna, de/sobre outras línguas, sobre a linguagem de um modo mais geral e sobre todos os demais sistemas semióticos. Desses saberes, evidentemente, também fazem parte as crenças, superstições, representações, mitos e preconceitos que circulam na sociedade em torno da língua/linguagem e que compõem o que se poderia chamar de imaginário lingüístico ou, sob outra ótica, de ideologia lingüística. Inclui-se também na educação lingüística o aprendizado das normas de comportamento lingüístico que regem a vida dos diversos grupos sociais, cada vez mais amplos e variados, em que o indivíduo vai ser chamado a se inserir.

\footnotetext{
${ }^{1} \mathrm{O}$ título deste artigo inspira-se diretamente num outro, de Aryon D. Rodrigues, "Tarefas da Lingüística no Brasil", publicado em 1967, e ainda hoje atual - o que certamente ilustra nossa dificuldade em propor as questões de língua e linguagem como questões relativas a uma política lingüística.
} 
Dentro de nossa perspectiva, portanto, é possível dizer que a educação lingüística de cada indivíduo começa logo no início de sua vida, quando, em suas interações com a família e a comunidade, adquire sua língua materna e, junto com ela, progressivamente, toda uma cultura de linguagem característica de seu meio social. Em muitas sociedades, como a brasileira, a educação lingüística pode ser objeto de uma formalização, de uma sistematização, de uma institucionalização, enfim, promovida pelas instâncias de poder que constituem o aparato estatal. É dessa educação lingüística institucionalizada - ou seja, da escola - que vamos tratar neste ensaio, ao tentarmos definir para ela algumas tarefas que nos parecem urgentes, no contexto social brasileiro.

\section{Língua e sociedade: uma crise}

A educação lingüística nas escolas brasileiras atravessa, no momento atual, uma crise inegável. Na verdade, ampliando o foco de análise, é possível dizer que é o panorama geral das relações entre língua e sociedade que exibe uma série de distorções e mal-entendidos. Existe, antes de mais nada, uma demanda social por educação lingüistica que suscita, da parte das diferentes instâncias ocupadas com o tema, conjuntos variados de respostas.

De um lado, as diferentes políticas oficiais de ensino (sobretudo as de âmbito federal) vêm gerando um acervo cada vez mais volumoso de reflexões teóricas, consubstanciadas em documentos da mais diversa natureza (leis, parâmetros curriculares, diretrizes, matrizes curriculares, princípios e critérios para avaliação de livros didáticos, etc.), aliadas a ações efetivas de intervenção nas práticas pedagógicas (exames de avaliação do ensino fundamental e médio, sistemas de avaliação de cursos superiores, programas de avaliação do livro didático, programas de formação docente etc.).

Do outro lado, todo esse esforço político oficial de atender às demandas de educação lingüística da sociedade é acompanhado num ritmo muitíssimo mais lento (e com impacto social muito menor) pelas instituições de ensino superior, ou seja, pelos cursos de Letras, mesmo os das universidades mais conceituadas.

Nas universidades públicas, dadas as condições de produção do trabalho acadêmico e do próprio conhecimento, a pesquisa desenvolvida 
não interfere, ou pouco interfere, nas áreas sociais mais amplas, incluída aí a escola (fundamental e média), que dela poderia se beneficiar de forma muito mais intensa e extensa. Nas próprias universidades, os debates e mesmo os resultados da pesquisa científica praticamente não ultrapassam o círculo restrito dos centros de investigação e das publicações especializadas, pouco numerosas e de distribuição deficiente. Muito freqüentemente, nem sequer a graduação em Letras dessas mesmas universidades sofre a influência saudável que se poderia esperar dessas investigações: os mesmos professores que realizam pesquisa de ponta se limitam, em seus cursos de graduação, a transmitir aos estudantes os postulados canônicos das diferentes disciplinas, sem renová-las com dados mais recentes, sem submetê-las a crítica, sem propor conceituações renovadas. Muito freqüente, também, é um certo desprezo pela formação de futuros docentes da escola fundamental e média, como se não fosse essa a vocação quase natural dos cursos de Letras. Há universidades, por exemplo, em que todas as disciplinas de sintaxe são ministradas sob a perspectiva da gramática gerativa, que, por não visar qualquer compromisso com o uso da linguagem, pouco ou nada pode subsidiar a escola na perspectiva da "virada pragmática" que hoje caracteriza a educação em língua materna. Por outro lado, os cursos universitários de gramática restringem-se, em geral, à gramática da frase, deixando de lado as regularidades da enunciação e do texto. Assim, nossos jovens professores tampouco têm acesso a alternativas eficientes de ensino da própria gramática que aprendem. Desse modo, provavelmente acabarão recorrendo às velhas práticas pedagógicas de ensino mecânico da tradição normativa - no que são incentivados, muitas vezes, nas chamadas "disciplinas pedagógicas" ou "de licenciatura". Nessas, com raras exceções, a chamada "didática específica", assim como a "prática de ensino", permanecem solidárias da tradicional concepção da educação em língua materna como um ensino sobre a língua (calcado na gramática tradicional) e a sua literatura. Num cenário como esse, o desenvolvimento da proficiência oral e escrita do aluno não é o objetivo primordial, razão pela qual a leitura, a produção de textos e a reflexão sobre a língua e a linguagem não são efetivamente encarados como objetos de ensino, ainda que apareçam como práticas escolares típicas da área.

No caso dos cursos de Letras das faculdades privadas, a situação é ainda mais precária: com poucas exceções, ali não se pratica nenhuma 
investigação, e o que se encontra nas graduações são currículos enrijecidos, impregnados em grande parte de um discurso normativoprescritivo acerca da língua, como se o destino do estudante de Letras fosse tornar-se um mero repetidor da doutrina gramatical tradicional. Reflexões de cunho científico sobre a língua e a linguagem ficam limitadas, em geral, a uma disciplina introdutória à Lingüística, de simples historiografia dessa ciência, historiografia que se detém (muitas vezes) onde deveria começar, isto é, no surgimento da Lingüística moderna, com a obra de Saussure e seus conceitos fundadores.

Muitos são os estudantes que se graduam em Letras sem jamais terem ouvido falar, em sua formação, de pragmática lingüística, de análise do discurso, de lingüística textual, de análise da conversação, de letramento, de gramaticalização, de gêneros textuais e de outras áreas de investigação que, paradoxalmente, se encontram em plena ebulição nos centros de pesquisa das grandes universidades brasileiras. Outros campos de estudo, como a sociolingüística e a semântica, que chegam a constituir, em alguns casos, disciplinas com esses mesmos nomes, são abordados de forma esquemática e pouco instigadora. Todas essas áreas de estudo, no entanto, são de fundamental importância para a formação de docentes capazes de promover a plena educação lingüística de seus alunos.

No terreno da Literatura, os problemas se repetem. A formação do professor nos cursos de Letras, no que diz respeito à Literatura, ainda se prende a uma teorização e a um estudo do cânon muito esquemáticos, sem se perceber quase nenhuma preocupação com a tarefa que deveria ser a principal do futuro professor de língua: a formação do leitor literário. Conforme está registrado em documento publicado pelo Ministério da Educação (BRASIL, 2003),

Persiste, ainda, a tradicional concepção informativa de literatura, entendida como conjunto de conhecimentos histórico-culturais e estéticos que se supõem poder fazer a mediação entre o leitor e a obra. Nessa concepção, o contato entre essas instâncias fica subordinado a critérios de avaliação e mecanismos de acesso atrelados a preceitos nem sempre muito adequados à compreensão da obra, por conta de uma origem de caráter normativo ou excessivamente canônico, que acabam perturbando o efetivo trabalho do leitor.

O resultado de tudo isso é que os professores do ensino básico, ao entrarem em contato com as fundamentações teóricas dos documentos 
que configuram as políticas oficiais de ensino, sentem nítida dificuldade de interagir com esses textos, o que faz surgir a necessidade de "formálos" para ler e interpretar os documentos oficiais - um esforço que poderia ser evitado se, desde a graduação, eles tivessem sido familiarizados com aquele tipo de reflexão e com aquelas propostas. Um exemplo disso ocorre, como se sabe, com o livro didático: as obras mais recomendadas nos processos de avaliação do Ministério da Educação, justamente por serem mais sintonizadas com propostas de ensino inovadoras, são evitadas pela maioria dos professores, que se sentem pouco habilitados a utilizá-las de modo proveitoso e eficiente.

Com isso, verifica-se uma situação de mal-estar em sala de aula, uma vez que o professor sabe - ou pelo menos ouviu dizer - que não deve mais se limitar à transmissão da gramática normativa, executada por meio dos exercícios mecânicos de classificação/reconhecimento de palavras/funções de palavras, mas não se sente seguro para substituir essa prática por "outra coisa". Sabe também que a função primordial da escola, sobretudo nas séries iniciais, é desenvolver as capacidades de leitura e de escrita dos alunos - no entanto, essa consciência não suscita a eliminação das práticas convencionais (e inúteis) do "ditado", da "redação" e da "separação de sílabas".

Abre-se, então, uma lacuna entre as propostas oficiais de ensino de língua, a formação docente nas universidades e as demandas sociais por uma educação capaz de assegurar os direitos lingüísticos do cidadão e de lhe permitir construir sua cidadania.

Essa lacuna acaba sendo preenchida, de maneira muito inadequada, pelas respostas oferecidas por instâncias desvinculadas da reflexão científica criteriosa e da política pública de educação lingüística, e muito mais ligadas às dinâmicas do mercado e das necessidades (reais ou supostas) por ele definidas. Trata-se do ressurgimento, na última década, dos antigos "consultórios gramaticais", que se aproveitam, agora, das tecnologias de comunicação mais avançadas para oferecer seus serviços: além das tradicionais colunas de jornal e de revista e dos livros do tipo "não erre mais", proliferaram nos últimos tempos os programas de rádio e de televisão, as páginas eletrônicas na internet, os cd-roms, as fitas de videocassete e os DVDS e até serviços de atendimento telefônico, todos destinados a ensinar o "bom português" ou a "língua certa" aos seus usuários-clientes-consumidores. Com respostas categóricas e rápidas, tais empreendimentos - precisamente por serem 
executados por pessoas sem formação adequada - se baseiam em concepções arcaicas e pré-científicas de língua e linguagem e contribuem, explítica ou veladamente, para a disseminação de preconceitos contra qualquer manifestação lingüística que não corresponda a uma "norma culta" extremamente idealizada e rígida, composta, em boa parte, de regras de uso da língua já caídas em obsolescência e preservadas, quando muito, em fórmulas fixas presentes em gêneros textuais bastante ritualizados (cf. BAGNO, 1999, 2000, 2003).

Outro tipo de resposta inadequada às demandas sociais de educação lingüística têm sido as recentes tentativas de legislar sobre questões de língua (FARACO, 2001). Por melhores que tenham sido as intenções desses projetos de lei, eles se baseiam essencialmente em preconceitos históricos e sociais (como o mito da unidade lingüística do Brasil) e recorrem a concepções de língua e de linguagem ultrapassadas há, no mínimo, cem anos. O forte apoio que esses projetos receberam - vindo de todos os espectros ideológicos - revela a pertinência desse tipo de questão para o convívio republicano e, portanto, a urgente necessidade de um amplo debate social sobre questões lingüísticas, um debate que inclua não somente os especialistas da área, mas todos os atores sociais implicados, no intuito de provocar uma reflexão mais consistentemente embasada sobre a língua e suas íntimas relações com a cultura e as estruturas sociais.

\section{Áreas de ação}

A tarefa mais urgente, nos parece, é promover a reflexão e a ação capazes de articular (i) as demandas sociais por uma educação lingüística de qualidade, (ii) as políticas públicas de ensino de língua e (iii) a pedagogia de educação em língua materna praticada na escola. Evidentemente, esse processo, se exitoso, viria a interferir na própria formação dos professores de português, o que decerto acarretaria uma reavaliação e reformulação dos cursos superiores de Letras - que parecem ainda se prender, já pela própria denominação, a estruturas sociais e ditames culturais do século XIX...

A partir da implantação oficial da Lingüística nos cursos superiores do Brasil (década de 1960), os diferentes campos de interesse das ciências da linguagem vêm experimentando um notável desenvolvimento em 
nosso país. Da multiplicidade de conhecimentos acumulados ao longo desse período, algumas áreas específicas de investigação se destacam - pelas opções teóricas que as sustentam e pelos resultados obtidos como as de maior vocação para contribuir para a constituição de uma política de educação lingüística. Vamos tratar de cada uma delas.

\section{Letramento}

Definido como "estado ou condição de quem não só sabe ler e escrever, mas exerce as práticas sociais de leitura e de escrita que circulam na sociedade em que vive, conjugando-as com as práticas sociais de interação oral" (SOARES, 1999, p. 3, grifos da autora), o conceito de letramento vem sendo amplamente utilizado nas reflexões teóricas e nas formulações de propostas práticas de educação em língua materna. Trata-se, efetivamente, de uma concepção de práticas de leitura/escrita que ultrapassa o conceito, mais restrito e mais convencional, de alfabetização. Nesse sentido, letrar não é simplesmente "ensinar a ler e a escrever", mas criar condições para que o indivíduo ou o grupo possa exercer a leitura e a escrita de maneira a se inserir do modo mais pleno e participativo na sociedade tipicamente letrada que é a nossa, especialmente no que diz respeito aos espaços mais institucionalizados do convívio republicano. A criação de tais condições é tarefa primordial de qualquer projeto de educação lingüística, uma vez que a inserção na sociedade letrada é requisito indispensável para a construção da cidadania e de uma sociedade democrática, além de constituir direito inalienável do cidadão. Embora o letramento não se restrinja às práticas caracteristicamente escolares, é a escola que, no Brasil, se responsabiliza por letrar, de modo sistemático, os cidadãos que a ela têm acesso. As condições de letramento oferecidas tradicionalmente pela escola, no entanto, não são estabelecidas com base num conjunto coerente de princípios teóricos e metodológicos, mas quase sempre são fruto da intuição e da criatividade dos docentes, quando não resultam de soluções de compromisso diante da precariedade material (como a prática das apostilas e, até recentemente, as aulas de "copiação" de unidades inteiras de livros, transcritas ou ditadas pelo professor, em função da quantidade insuficiente de exemplares na escola) ou, ainda, simplesmente atrelam-se a determinadas atividades cristalizadas, como a já muito criticada prática da "redação" escolar. 
O conceito de letramento vem se mostrando tão produtivo que seu uso tem sido ampliado para referir-se ao domínio das diversas funções sociais e das habilidades de uma pessoa em outros campos culturalmente estratégicos, além do campo da leitura/escrita de textos propriamente ditos. Fala-se, então, por exemplo, do letramento digital - as práticas sociais relativas ao uso das tecnologias da informática e mesmo do letramento matemático. No que diz respeito à pedagogia de língua materna, o simples reconhecimento da coexistência do letramento stricto sensu com esses outros, e mais ainda a necessária interpenetração entre eles, convida à reformulação de nossas representações da escrita e, portanto, de nossas crenças a respeito das formas mais adequadas de ensiná-la.

Numa outra vertente, esse mesmo ensino em muito poderá se beneficiar se reconhecer e mobilizar, como parte de suas estratégias, as práticas letradas características das culturas juvenis contemporâneas grafites, fanzines, raps, chats, blogs etc. - e de toda uma produção de material letrado voltada para esses jovens - revistas, suplementos de jornais, páginas eletrônicas etc. Da mesma forma, considerando-se o significado político e social das práticas de letramento características das camadas populares, e em particular suas crenças e representações relativas à escrita, sua descrição em muito contribuiria para caracterizar o perfil cultural da maior parte do alunado de nossas escolas públicas, possibilitando um diálogo ao mesmo tempo mais respeitoso, em termos éticos e políticos, e mais bem orientado, do ponto de vista didáticopedagógico.

Uma das tarefas da educação lingüística seria, então, oferecer propostas teóricas e práticas para levar a escola brasileira a desenvolver, de modo consciente e sistemático, o letramento de seus alunos, isto é, garantir a eles a possibilidade de participar e interferir na construção de uma sociedade letrada. O debate em torno do letramento implica, necessariamente, a discussão de outros aspectos fundamentais da linguagem como atividade social: as relações entre lingua falada e lingua escrita (MARCUSCHI, 2001) e o conceito de gêneros textuais (DIONÍSIO et al., 2002), bem como o letramento literário (MARTINS et al., 1999; PAIVA et al., 2003). 


\section{Português Brasileiro}

O reconhecimento das especificidades do português brasileiro, aliado ao esforço por descrevê-las com instrumental científico adequado, a partir de metodologia criteriosa de coleta de dados, tem levado à constituição de grandes acervos de língua falada e escrita, que vêm servindo de base para a produção de obras teóricas, gramáticas descritivas e dicionários de uso. Embora concentrando-se, em grande parte, na atividade lingüística dos falantes urbanos de escolaridade superior (os chamados "falantes cultos"), a investigação do português brasileiro também inclui projetos de descrição e análise das variedades rurais, "rurbanas" (BORTONI-RICARDO, 2004) e/ou da fala de cidadãos urbanos de escolaridade fundamental e média e analfabetos (ver levantamento dessas pesquisas em PAIVA e SCHERRE, 1999). No ensino de língua praticado nas escolas, porém, as especificidades do português brasileiro são pouco ou mal reconhecidas e, no mais das vezes, quando mencionadas, se destinam a condenar os supostos "erros" cometidos pelos brasileiros ao falar/escrever. Nesse particular, uma das tarefas da educação lingüística seria propor estratégias para que o conhecimento acumulado acerca das características específicas da língua majoritária dos brasileiros alcançasse o ensino, interferisse na produção de materiais didáticos e, com isso, propiciasse o surgimento, na sociedade em geral, de uma atitude não depreciativa - e, ao contrário, valorizadora - das regras gramaticais caracteristicamente brasileiras e já definitivamente incorporadas à nossa atividade lingüística oral e escrita diária.

Tarefa não menos urgente é a produção de uma gramática de referência do português brasileiro, não normativa e suficientemente acessível ao leitor comum. Essa obra deveria propor a aceitação cabal e sem rodeios das formas lingüísticas já definitivamente incorporadas à língua comum de todos os brasileiros, inclusive os classificados de "cultos" pela pesquisa lingüística. É inadmissível que tantas formas lingüísticas características do português brasileiro - presentes inclusive e há muito tempo na língua escrita mais monitorada e na produção literária - continuem sendo tratadas como "erros a serem evitados" pelos compêndios gramaticais, pelos livros didáticos e pelo ensino de modo geral. Da mesma forma, uma descrição cientificamente válida de nossas variedades regionais e, particularmente, das constantes do português dito popular, em análise contrastiva com as variedades ditas cultas, inclusive no que diz respeito ao que Pinto (1990) denominou 
"português popular escrito", permitiria ao professor conhecer melhor o universo lingüístico-cultural de seus alunos. E ainda forneceria material para análises que não se restringissem às variedades cultas, impedindo que a escola identifique a norma culta como "a Língua Portuguesa”.

\section{Norma, variação \& mudança lingüística}

O reconhecimento da natureza essencialmente heterogênea, variável e mutante das línguas humanas ainda não ganhou o senso comum, e o imaginário lingüístico que vigora na sociedade se estrutura em torno de uma noção estática de língua, sempre encarada como o modelo de "pureza" e "correção" cristalizado na obra dos grandes escritores e descrito-prescrito nos compêndios gramaticais normativos. Nesse conjunto de crenças, o que se entende por "língua" é uma entidade homogênea, monolítica, não só exterior ao indivíduo, mas que necessita, inclusive, de ser "protegida" do "mau uso" ou do "abuso" que esse mesmo indivíduo possa vir a "cometer" contra ela. A variação, quando reconhecida, é simplesmente sinônimo de "erro".

Para agravar esse quadro, esse modelo idealizado de "língua certa" recebe, da parte de seus defensores e dos não-especialistas, a designação de "norma culta". Ora, essa mesma expressão é empregada, em muitos trabalhos científicos, para designar o conjunto de regularidades gramaticais detectáveis no uso efetivo da língua por parte dos "falantes cultos" - cidadãos urbanos com escolaridade superior completa - em suas interações sociais. Tem-se, com isso, uma duplicidade de conceitos abrigados sob o mesmo rótulo de "norma culta": um conceito normativo, isto é, de como a língua "deve ser", e um conceito que se aplica ao que é normal na língua (ou mais precisamente numa variedade específica da língua, a dos cidadãos urbanos mais letrados), isto é, como a língua "é" de fato. Diante disso, tem sido proposto o uso do termo norma-padrão para designar o conjunto de regras gramaticais padronizadas e erigidas como modelo a ser seguido para o "bom uso" da língua (LUCCHESI, 2002; FARACO, 2002; cf. BAGNO, 2003, para uma proposta mais radical de terminologia).

Uma política de educação lingüística coerente com os avanços teóricos das ciências da linguagem tem de se valer de tudo o que já se sabe acerca dos fenômenos de variação no português brasileiro em sua 
relação com os fenômenos de mudança lingüística. Espera-se, pois, uma educação lingüística que ofereça estratégias para um tratamento da variação lingüistica que não se limite a fenômenos de prosódia ("sotaque") ou de léxico ("aipim", "mandioca", "macaxeira"), mas que evidencie o fato de que a língua apresenta variação em todos os seus níveis, e que essa variação da língua está indissoluvelmente associada à variação social. Este tratamento mais consistente da variação deve mostrar que também na língua falada e escrita pelas camadas privilegiadas da população ("falantes cultos") ocorrem usos divergentes dos estipulados pela norma-padrão canônica.

Também é preciso encontrar modos que possibilitem um tratamento consistente dos fenômenos da mudança lingüística, a fim de mostrar que a língua está constantemente em transformação, que essa tendência à mudança é da própria natureza das línguas humanas. Essa abordagem não deve se limitar a fatos diacrônicos, mas contemplar também fatos de variação sincrônica que apontam para uma provável mudança futura. Deve igualmente levar à conscientização de que a mudança não é para pior nem para melhor, mas que é simplesmente mudança, adequação do sistema lingüístico às necessidades de interação social dos falantes, necessidades que se modificam ao longo da história. Igualmente conveniente é dissipar a noção corriqueira de que a mudança representa um "empobrecimento" da língua. Nesse sentido, o ensino de português teria muito a ganhar com uma abordagem bem sistematizada dos fenômenos de gramaticalização - processo considerado por muitos estudiosos como principal impulsionador da mudança lingüística (CASTILHO, 1997).

Urge, também, uma abordagem bem esclarecida do fenômeno da norma lingüística, num esforço de evidenciar seu vínculo indissociável com as outras normas que regem a vida em sociedade. Nesse sentido, cabe mostrar que a norma-padrão (o ideal de "língua certa" que circula no senso comum) é o construto cultural de um determinado momento histórico, vinculado a determinadas classes sociais, a determinadas concepções de sociedade e a determinados tipos de relações de controle e coerção social (BOURDIEU, 1996; SOARES, 1986). Não se trata, evidentemente, de repudiar as regras lingüísticas padronizadas, mas de reconhecer que elas estão sujeitas, como todas as demais normas sociais, à obsolescência, à crítica e à reformulação (NEVES, 2003; ALÉONG, 2001; REY, 2001). É tarefa da educação lingüística 
politizar a discussão, na escola, acerca das noções de certo e errado que circulam na sociedade em torno de questões lingüísticas.

\section{Reflexão lingüística}

Muito se tem discutido sobre se cabe ou não à escola "ensinar gramática". A questão, colocada nesses termos simplistas, carece de todo sentido. Logo de saída, o conceito de "gramática" com que se opera nessas discussões é extremamente redutor: não se trata ali da gramática tal como é entendida pelas teorias lingüísticas modernas - a descrição das regras de funcionamento de uma dada língua ou o conhecimento intuitivo que todo falante tem do funcionamento de sua língua materna -, mas de um conceito marcadamente normativo-prescritivo de gramática, isto é, conjunto de regras que prescrevem o uso considerado (por alguns setores privilegiados da sociedade) correto da língua escrita e falada. Mais redutor ainda, e mais freqüente, é a compreensão de gramática como mera nomenclatura gramatical. Pesquisas têm revelado que, apesar de todos os esforços de renovação das práticas de ensino de língua empreendidos nos últimos tempos, ainda predomina na maioria das escolas brasileiras uma concepção de "aula de português" que se reduz ao reconhecimento/classificação de palavras e funções de palavras e à rotulação dessas classes/funções segundo a nomenclatura gramatical tradicional (ANTUNES, 2003). Assim, "saber português" equivale a ser capaz de distinguir o "complemento nominal" do "adjunto adnominal" ou de identificar uma "oração subordinada substantiva objetiva direta”. O problema, aqui, não está na nomenclatura em si, mas na crença (falaciosa) de que conhecer os rótulos e suas definições e/ou ser capaz de empreender análises sintáticas é condição suficiente para compreender o funcionamento da língua e, graças a esse "conhecimento", ser capaz de "falar e escrever bem".

A verdadeira questão é admitir que há lugar na escola para um estudo sistematizado sobre a língua, um estudo que leve o aluno-falante a se conscientizar das regularidades presentes em sua atividade lingüística e do proveito que pode lhe advir do conhecimento dessas regularidades - e há consenso entre os estudiosos da área de que, sim, esse lugar para a reflexão lingüística existe e que ela deve constituir um dos eixos principais da educação lingüística (TRAVAGLIA, 1995, 2003; POSSENTI, 1996; PERINI, 1997; NEVES, 1991, 2003; BAGNO, STUBBS 
\& GAGNÉ, 2002). Nesse sentido, também é urgente estender a percepção e a análise das regularidades lingüísticas a níveis superiores ao da frase, na direção de uma "gramática do texto" já preconizada pelos Parâmetros Curriculares Nacionais, por exemplo, mas ainda pouco assimilada e menos ainda praticada. Em especial, é preciso reconhecer como objeto de estudo/ensino, embora de forma evidentemente expandida e aprofundada, o que Benveniste chamou de "aparelho formal da enunciação", estabelecendo-se também nesse nível as constantes que caracterizam o funcionamento do português.

Nessas condições, a construção e a apropriação de um discurso gramatical pedagogicamente útil e relevante dependerá da reinstauração do sentido. De fato, se o saber fizer sentido para o aluno, se o sistema apresentado for organizado de maneira coerente e não se reduzir a uma classificação ou a uma etiquetagem descoladas do uso e da significação, se não se restringir à palavra e à frase, a gramática aparecerá mais conectada com a língua, tal como a exploram os diferentes usuários, e não será mais vista como um discurso abstrato, inapropriável porque inadequado.

Com isso, outra tarefa dessa educação lingüística será propor estratégias para que se estabeleça no ensino um conceito claro de gramática como o próprio sistema de regras de funcionamento da língua, ao invés de se apresentar gramática como um conjunto normatizado de regras de uso, ou gramática como a descrição das entidades da língua e sua função. Estratégias que também favoreçam um entendimento das gramáticas normativa e descritiva, apresentadas segundo a funcionalidade de cada um desses instrumentais de estudo da língua, sem que haja predomínio de um deles. Fica evidente, desde logo, que não cabe à escola rejeitar as regras normatizadas - o que seria um absurdo, uma vez que elas constituem um elemento importante da cultura nacional e seu domínio é reconhecido como fator de prestígio social -, mas, sim, apresentá-las ao lado das regras alternativas, as que já caracterizam o português brasileiro contemporâneo e já se incorporaram definitivamente à gramática da nossa língua, inclusive em suas manifestações escritas mais monitoradas. Nesse sentido, a metalinguagem pode se mostrar um instrumento útil, desde que seja um meio para a compreensão do aspecto lingüístico estudado e não um fim em si mesma; desde que seja o ponto de chegada da reflexão sobre a língua e não o ponto de partida. 


\section{Literatura}

Faz parte da educação lingüística o acesso pleno e frutífero ao patrimônio literário de uma nação e de um idioma. Entretanto, na escola brasileira, e até os dias de hoje, a educação literária ainda se resume aos seguintes procedimentos (listados em BRASIL, 2003):

1 Ligar a literatura a uma suposta evolução cronológica, o que remete à necessidade de "começar pelo começo", exigindo do aluno a aproximação a padrões e usos lingüísticos muito distantes de seus usos mais imediatos. A fruição dos textos originais, exigência básica do ensino da literatura, acaba prejudicada por esse distanciamento.

2 Fornecer um quadro da época, com os principais acontecimentos.

3 Informar sobre as tendências estéticas em vigor: as Escolas Literárias. $\mathrm{Ou}$, ainda, arrolar as características da Escola a que pertence $(\mathrm{m}) \mathrm{o}(\mathrm{s})$ autor(es) estudado(s).

4 Apresentar dados biográficos do autor.

5 Resumir a obra: se prosa: tema, personagens principais, enredo, espaço e tempo. Se poesia: o conteúdo, as rimas, o ritmo, as imagens.

Não se pode, é claro, desconsiderar a pertinência da contextualização da obra literária. No entanto, a insistência quase exclusiva nessa contextualização faz com que as informações sobre a literatura tenham se constituído na totalidade da educação literária, principalmente no curso médio. Desse modo, fica relegada a segundo plano a leitura efetiva do texto, substituída por sua paráfrase ou comentário. Ora, a concepção da literatura como conjunto de monumentos culturais, subjacente a tais práticas, foi criticada na área dos estudos literários, o que levou à exigência de uma prioridade do contato, o mais direto possível, com o texto literário. Por conseguinte, se alterou também a expectativa acerca do leitor, visto hoje, essencialmente, como um sujeito capaz de usufruir das variadas possibilidades que um texto literário oferece. Essas alterações postulam uma nítida transformação das propostas de ensino. Assim, de preferência a uma visão sistemática da história e da teoria literárias, é mais pertinente, sem dúvida, familiarizar o aluno com uma atitude de disponibilidade diante do texto literário, tornando esse contato uma efetiva experiência. Por experiência, aqui, se entende 
um contato primordialmente sensível entre o aluno e o texto, de tal forma que desse contato resulte alguma mudança em seu modo de perceber a realidade. Esse papel que o texto literário pode exercer sobre o alunoleitor extrapola em muito sua função informativa e cultural; e decorre do que se convencionou chamar sua "natureza estética": dentre todas as modalidades e variações que a linguagem verbal assume, é o texto literário que pode levar a limites sempre extremos as possibilidades da lingua. Isso se dá por conta da liberdade que o fazer literário exige para a sua constituição. (BRASIL, 2003).

Não se trata, evidentemente, de elevar a literatura a um patamar de superioridade em relação aos demais usos da língua, mas de reconhecer, antes de mais nada, a singularidade da obra literária e, no plano social, sua importância na formação plena do indivíduo, em sua inserção na sociedade letrada a que pertence e em sua participação na produção cultural brasileira e universal.

\section{Direitos lingüísticos}

A história da formação da sociedade brasileira revela o empenho constante, por parte das camadas sociais dominantes, de criar a imagem de um país monolíngüe, onde todos os habitantes se entendem perfeitamente e vivem, por isso, em total harmonia. O mito da língua única, para se constituir, exigiu ao longo da história uma política lingüística essencialmente autoritária, consubstanciada em medidas repressoras que incluíram, por exemplo, a proibição, por parte da metrópole portuguesa, no século XVIII, da utilização da língua geral de origem tupi (a mais falada, então, em todo o território) com finalidades pedagógicas, ou a perseguição dos falantes de dialetos alemães e italianos no Sul do país, durante a ditadura de Getúlio Vargas, que transformou o uso desses dialetos em "crime idiomático", passível de prisão sumária (OLIVEIRA, 2000). Com tudo isso, a crença na unidade lingüística do Brasil permanece viva em nossa cultura, embora o Brasil seja classificado pela UnEsCo como um país multilíngüe, onde são faladas, além do português brasileiro, cerca de 200 línguas diferentes, das quais umas 170 autóctones (indígenas) e as demais, alóctones (trazidas pelos imigrantes europeus e asiáticos).

O reconhecimento dos diversos direitos lingüísticos desses falantes - explicitados na Declaração Universal dos Direitos Lingüísticos, assinada em 1996 sob os auspícios da UNESCO - revela não somente a 
necessidade de ações políticas que visem garanti-los, como também a necessidade de criar, na sociedade mais ampla, uma consciência dessa realidade multilíngüe, que deve ser considerada como uma riqueza cultural da nação, e não como um perigo à sua unidade. Essa conscientização tem na escola um de seus promotores naturais, e uma das tarefas da educação lingüística para a cidadania tem de ser a formação de uma cultura do respeito à diferença e à pluralidade.

Esse respeito à diferença não concerne apenas os falantes brasileiros de outras línguas, mas também os falantes de variedades do português brasileiro tradicionalmente estigmatizados por causa das regras características de seu modo de falar. Como se sabe, o preconceito lançado sobre essas variedades é, essencialmente, a transferência, para o plano lingüístico, de preconceitos que são, no fundo, sociais. Se uma pessoa é pobre, se tem origem rural, se não tem educação formal, se provém de uma região considerada atrasada, sua maneira de falar a língua será considerada (como suposta decorrência "natural" desses fatos) "pobre", "tosca", "inculta", "atrasada" etc. Ora, um dos princípios norteadores de toda a ciência lingüística moderna é o de que todas as línguas e todas as variedades de língua se equivalem no que diz respeito a suas complexidades estruturais e a seus recursos expressivos, não existindo, portanto, línguas/variedades "primitivas", nem línguas/variedades "inferiores" a outras, supostamente mais "desenvolvidas". Assim, a simples afirmação de que um indivíduo "fala errado" já constitui um atentado aos seus direitos lingüísticos. Nesse sentido, uma das tarefas mais delicadas da educação lingüística é deixar bem claro e evidente que o respeito às variedades lingüísticas estigmatizadas não significa negar aos seus falantes o direito ao pleno conbecimento e domínio das formas lingüisticas de prestígio. Essas formas padronizadas se vinculam, tradicionalmente, às práticas sociais de letramento mais prestigiadas, e é dever do Estado, e, portanto, da escola, garantir que, sem prejuízo de sua variedade de origem, todos os cidadãos possam conhecer e utilizar, conforme lhes pareça conveniente, as formas lingüísticas que, por razões históricas, culturais e sociais (e não por supostas qualidades lingüísticas intrínsecas), foram erigidas em padrão de comportamento lingüístico apropriado às interações sociais mais monitoradas, mais formais, faladas e/ou escritas.

Por outro lado, considerando-se o papel estratégico da leitura num sem-número de atividades socialmente relevantes, em termos políticos e culturais, pode-se pensar que, para além do direito à sua 
língua e/ou variedade materna, associado ao direito de aprendizagem e apropriação das variedades de prestígio, um dos direitos lingüísticos inalienáveis do cidadão consistiria no direito à leitura e, particularmente, no direito à literatura. ${ }^{2}$ O patrimônio cultural representado pelas literaturas, e em especial pela literatura brasileira, não deve nem ter sua circulação restrita à escola, nem ser privilégio de uns poucos. Para que as medidas e os equipamentos culturais necessários sejam criados na quantidade e com a qualidade necessárias, será preciso, antes de mais nada, reconhecer esse direito e, portanto, incluí-lo numa pauta como a que aqui propomos.

\section{Conclusão}

Até por sua vinculação direta com os direitos do cidadão, as tarefas acima listadas constituem claramente uma agenda estratégica, capaz de conduzir à formulação de uma política lingüistica ou, mais precisamente, uma política de educação lingüística, ao mesmo tempo adequada ao momento político nacional e cientificamente consistente. Por isso mesmo, não hesitamos, no decorrer desta discussão, em empregar precisamente essa expressão. Se assim de fato se apresentam as coisas, a conclusão natural é a de que o planejamento e a implementação dessa política cabem, primordialmente, ao Estado e às suas instituições dedicadas à gestão de tais áreas da vida social. Parece necessário, portanto, senão urgente, a instituição de um fórum de debates em torno desses pontos, no qual se encontrem todos os atores sociais implicados na educação lingüística, desde os que atuam em sala de aula e lidam diretamente com as dificuldades da educação em língua materna, até os que tomam as decisões políticas nos níveis hierárquicos superiores, passando, sem dúvida, pelas esferas da formação dos docentes e da pesquisa científica.

\footnotetext{
${ }^{2}$ Neste momento, estamos aproveitando uma sugestão de Antônio Cândido, em palestra para o projeto "Leitor Infinito", da Secretaria de Cultura do Município de São Paulo (1990). Na ocasião, talvez pioneiramente, no Brasil, a então Secretária, Profa. Marilena Chauí, propôs para a sua Secretaria uma política cultural em que o direito à leitura ocupava um lugar central, razão pela qual o referido projeto tinha como objetivo dotar as bibliotecas públicas municipais dos mecanismos e procedimentos necessários para garantir à população esse direito.
} 


\section{Referências}

ALÉONG, S. Normas lingüísticas e normas sociais: uma perspectiva antropológica. In: BAGNO, M. (Org.). Norma lingüística. São Paulo: Loyola, 2001.

ANTUNES, I. Aula de português: encontro E interação. São Paulo: Parábola, 2003.

BAGNO, M. Preconceito lingüistico: o que é, como se faz. São Paulo: Loyola, 1999.

BAGNO, M. Dramática da lingua portuguesa: tradição gramatical, mídia E exclusão social. São Paulo: Loyola, 2000.

BAGNO, M. A norma oculta: lingua \& poder na sociedade brasileira. São Paulo: Parábola, 2003.

BAGNO, M.; STUBBS, M.; GAGNÉ, G. Lingua materna: letramento, variação Eensino. São Paulo: Parábola, 2002.

BORTONI-RICARDO, S. M. Educação em lingua materna: a sociolingüistica na sala de aula. São Paulo: Parábola, 2004.

BOURDIEU, P. A economia das trocas lingüísticas. São Paulo: Edusp, 1996.

BRASIL. Critérios para avaliação de livros didáticos de português para o ensino médio. Brasília: Ministério da Educação/SEMTEC, 2003.

CASTILHO, A. A gramaticalização. Estudos Lingüisticos e Literários, Salvador, n. 19, p. 25-64, 1997.

DIONÍSIO, A.; MACHADO, A. R.; BEZERRA, M. A. (Org.). Gêneros textuais: teoria e ensino. Rio de Janeiro: Lucerna, 2002.

FARACO, C. A. (Org.). Estrangeirismos: guerras em torno das linguas. São Paulo: Parábola, 2001.

FARACO, C. A. Norma-padrão brasileira: desembaraçando alguns nós. In: BAGNO, M. (Org.). Lingüistica da norma. São Paulo: Loyola, 2002.

LUCCHESI, D. Norma lingüística e realidade social. In: BAGNO, M. (Org.). Lingüística da norma. São Paulo: Loyola, 2002.

MARCUSCHI, L. A. Da fala para a escrita: exercícios de retextualização. São Paulo: Cortez, 2001. 
MARTINS, A. A.; BRANDÃO, H. M. B.; MACHADO, M.Z.V. A escolarização da leitura literária: o jogo do livro infantil e juvenil. Belo Horizonte: CEALE/Autêntica, 1999.

NEVES, M. H. Gramática na escola. São Paulo: Contexto, 1991.

NEVES, M. H. Que gramática ensinar na escola? São Paulo: Contexto, 2003.

OLIVEIRA, G. M. Brasileiro fala português: monolingüismo e preconceito lingüístico. In: SILVA, F.; MOURA, H. (Org.). O direito à fala: a questão do preconceito lingüistico. Florianópolis: Insular, 2000.

PAIVA, A.; MARTINS, A.; PAULINO, G.; VERSIANI, Z. (Org.). Literatura e letramento: espaços, suportes e interfaces - o jogo do livro. Belo Horizonte: Autêntica/CEALE, 2003.

PAIVA, M. C.; SCHERRE, M. M. P. Retrospectiva sociolingüística: contribuições do PEUL. D.E.L.T.A., São Paulo, 15: 201-232, 1999.

PERINI, M. A. Sofrendo a gramática. São Paulo: Ática, 1997.

PINTO, E. P. O português popular escrito. São Paulo: Contexto, 1990.

POSSENTI, S. Porque (não) ensinargramática na escola. Campinas: Mercado de Letras, 1996.

REY, A. Usos, julgamentos e prescrições lingüisticas. In: BAGNO, M. (Org.). Norma lingüistica. São Paulo: Loyola, 2001.

SOARES, M. Linguagem e escola: uma perspectiva social. São Paulo: Ática, 1986.

SOARES, M. Português: uma proposta para o letramento. Livro do Professor. São Paulo: Moderna, 1999.

TRAVAGLIA, L. C. Gramática e interação. São Paulo: Cortez, 1995.

TRAVAGLIA, L. C. Gramática: ensino plural. São Paulo: Cortez, 2003. 